\title{
REALIDAD E ILUSIÓN EN LA POESÍA LATINA TARDOANTIGUA: NOTAS A PROPÓSITO DE ESTÉTICA LITERARIA
}

One of the outstanding literary features of the latest old latin poets (Pentadius, Optatianus Porfyrius, Tiberianus and, mainly, Ausonius) is undoubtedly the detailed description and close imitation of reality, even in its most ambiguous aspects whether they are pellucidness, touches of light and shade, gleams, delusion or an odd blend of truth and deceit - and thus they attempt to excel their classical models, closely related to the aesthetics which rules other techniques and arts at the time. Such an aesthetic approach affects both matter and form (echoic verses, centos, carmina figurata, etc.).

\section{A modo de introducción}

1. Cuenta Plinio una anécdota bien conocida: Zeuxis y Parrasio, los más grandes pintores de su tiempo, concursaron para decidir quién obtenía la palma. Zeuxis pintó unas uvas tan maravillosamente logradas que las aves vinieron a picarlas; pero Parrasio se limitó a presentar un paño; Zeuxis - lleno de orgullo por el veredicto de las aves--- intentó retirarlo para ver la obra de su contrincante; al comprender su error, cedió la palma de la victoria a Parrasio porque si él había logrado engañar a los pájaros, Parrasio lo había engañado a él '.

\footnotetext{
1 Hist. Nat. XXXV 65. Sigo la edición de J. M. Croisille (París 1985):
}

Descendisse hic (Parrhasius) in certamen cum Zeuxide traditur et, cum ille detulisset uuas pictas tanto successu, ut in scaenam aues aduolarent, ipse detulisse linteum pictum ita ueritate repraesentata, ut Zeuxis alitum iudicio tumens flagitaret tandem remoto linteo ostendi picturam atque intellecto errore concederet palmam ingenuo pudore, quoniam ipse uolucres fefellisset, Parrhasius autem se artificem.

Sigue contando Plinio (ibidem) que también pintó Zeuxis en otra ocasión un niño con unas uvas; de nuevo vinieron los pájaros a comerlas, causando la ira del artista contra su obra, pues si bien había logrado la perfección en las uvas, el niño no estaba tan bien representado como para asustar a las aves. 
En esta anécdota queda ilustrada de modo ejemplar la máxima que rige la técnica creativa de la Antigüedad: ars est celare artem $^{1 \text { bis. Tal }}$ sentencia gobernó los espíritus no sólo de los llamados artistas plásticos, sino de todos cuantos aspiraban a lograr la perfección de su obra, fuere cual fuere el dominio en que ejercian su técnica; en realidad, con ella quedaba definida la esencia del arte clásico, pues fue aspiración constante de los antiguos emular - con la obra nacida del hombre la naturaleza circundante. De modo que la perfección equivalía a la adecuación entre el objeto artístico (pintura, escultura, melodía, etc.) y la realidad objetiva, sin que de ningún modo pudiera percibirse la técnica con que tal adecuación se había logrado.

2. Pero es bien sabido que no todos los artistas perciben la realidad del mismo modo, pues siempre la interpretación que de ella se hace tiene carácter selectivo ${ }^{2}$. La selección se efectúa de acuerdo, en primer lugar, con la sensibilidad del creador; en segundo, con la sensibilidad del contexto (temporal, geográfico, social, cultural, ideológico, etc.) que enmarca la actividad del creador. Por ello se habla del estilo de un autor, o del gusto creativo de una época. Y así, el problema fundamental ...en la medida en que está en la base de la creación - cuando se aborda la cuestión de la génesis de una obra, estriba en definir con exactitud cuál ha sido el "punto de vista», la posición desde la que el autor ha hecho su personal interpretación de la realidad.

Es por tanto - o al menos así lo entendieron los antiguos - la creación una mimesis ${ }^{3}$, no una semiosis, cuya originalidad consiste precisamente en que la selección de elementos relevantes efectuada resulte eficaz, o lo que es lo mismo, esencialmente creible. Se suele situar al espectador (incluido el lector) ante una sutil falacia, cuya principal virtud ha de ser su capacidad por sustituir la realidad imitada. Queda así creado un efecto ilusorio en el que, si el autor es grande, puede mover a su antojo al espectador. La fantasía cobra corporeidad y ya todo parece real $^{4}$.

I bis Una formulación personal de la máxima puede leerse en Ovid., Met. X 252: ars adeo latet arte sua (a propósito de la historia de Pigmalión).

${ }^{2}$ Cf. L. Grassi-M. Pepe, Dizionario della Critica d'Arte, Turin 1978, vol. I, pp. 242-243, s.u. "Illusione e Illusionismo".

${ }^{3}$ Es preciso citar desde ahora un libro clásico: E. Auerbach, Mimesis: La representación de la realidad en la literatura occidental, México-Buenos Aires 1950 (1942).

4 Esta estética manierista dominó a los artistas y a los tratadistas del xvil; así M. Boschini (1660) afirma: "Perché in fin la Pitura non è altro / Che un ingano de l'ochio certamente; / $\mathrm{E}$ quel, che in l'inganar xe più valente, / xe certo anche stimà per el più scaltro" (p. 80; tomado de Grassi-Pepe, Dizionario della Critica d'Arte, ya cit., vol. I. p. 256, s.u. "Inganno"). 
No hace falta decir que cada autor, cada época, se han servido en distinta medida de este recurso; y esa diferente medida es, precisamente, la que define la estética del autor o de la época en cuestión. Quisiera mostrar en las páginas que siguen algunos de los recursos creativos que ilustran el quehacer de los poetas latinos tardoantiguos, y que considero importantes para comprender cuál ha sido su posición estética ante la realidad, posición que, en sentido amplio, parece definir a todo su momento cultural, pues tales recursos pueden observarse también en otros artistas de su época.

3. La poesia latina tardoantigua no ha gozado, en general, de aprecio entre los criticos, pues se entiende que vive fuertemente dependiente de la clásica, sin conseguir en ningún momento sus altos vuelos de contenido y forma. Es más, los poetas tardoantiguos se han dejado tentar con excesiva frecuencia por un estéril preciosismo, o mejor, virtuosismo creativo donde la forma ha primado hasta límites absurdos sobre el contenido; no existe, pues, en ella ese sano equilibrio que debe caracterizar lo clásico, lo modélico, si se quiere. Pero me parece que este tipo de valoración obedece más bien a un prejuicio según el cual lo que para nosotros es bello, es lo mejor; dicho de otro modo, al situar como ejemplo arquetípico de lo bello el arte clásico, todo lo que exceda sus límites entra dentro del campo de lo no-clásico, o lo que es lo mismo, del arte de segundo orden. Esta forma de enjuiciar la creación artística, si bien permite una valoración esteticista - cuasi escolar, en la medida que establece prioridades y excelencias-, nos aleja de todo aquello que fue creado en un medio diferente y se niega a recuperar sus aciertos. Evidentemente, hace mucho que se traspasó el rígido normativismo academicista pero quedan, desde mi punto de vista, líneas sin subrayar $^{5}$.

"Ver Y.-M. Duval, "La poésie latine au IV" siècle de notre ère», Bull. Assoc. Guill. Budé 1987, pp. 165-192, donde se hace presentación, explicación y defensa de la poesía de este momento; también puede consultarse aunque con mayor concisión E. Fernández Vallina, "Claudiano y Rutilio Namaciano: de sus poéticas de la descripción", Actas del VII Congreso Español de Estudios Clásicos (Madrid, 20)-24 de abril de 1987), Madrid 1989, vol. II, pp. 581-586. El estudio de E. Sánchez Salor, "La última poesía latino-profana: su ambiente», EC 25, 1981-1982, pp. 111-162, se refiere a autores del siglo v; para el análisis de su estética literaria vid. en particular las pp. 137-162. Del mismo autor: "Hacia una poética de Ausonio", Hahis 7, 1976. pp. 159-186. 
El reflejo

4. Leamos el siguiente pasaje - uno de los más celebrados y, por tanto, comentados - del Mosella de Ausonio ${ }^{6}$ :

\begin{abstract}
illa fruenda palam species, cum glaucus opaco
respondet colli fluuius, frondere uidentur

fluminei latices et palmite consitus amnis,

quis color ille uadis, seras cum propulit umbras

Hesperus et uiridi perfundit monte Mosellam!

tota natant crispis iuga motibus et tremit absens

pampinus et uitreis uindemia turget in undis.

adnumerat uirides derisus nauita uites,

nauita caudiceo fluitans super aequora lembo

per medium, qua sese amni confundit imago

collis et umbrarum confinia conserit amnis?
\end{abstract}

Es dificil encontrar en la poesía latina de otros momentos anteriores algo parecido; no se trata sólo de que en este texto $-\mathrm{y}$ en buena parte del resto del poema ausoniano - la descripción de la naturaleza (descriptio naturae) aparezca como tema dominante ${ }^{8}$, lo que ya de por sí resultaría en cierto modo una novedad, sino que además el poeta ha querido presentarnos una visión muy especial de esa naturaleza: a saber, el diálogo sutil que se establece entre los distintos elementos que la integran - colinas, vides, río de aguas cristalinas-, mediante un juego exquisito de reflejos y sombras, ante el que el hombre - elemento central de buena parte de la poesía clásica - se siente superado, o por decirlo con palabras de Ausonio, derisus (v. 196), mostrando una suerte de impotencia con relación al mundo que lo circunda. En realidad, el

- Decimi Magni Ausonii Burdigalensis Opuscula, ed. S. Prete, Leipzig 1978. Ahora, ya se puede leer versión española de los escritos del poeta de Burdeos: D. M.

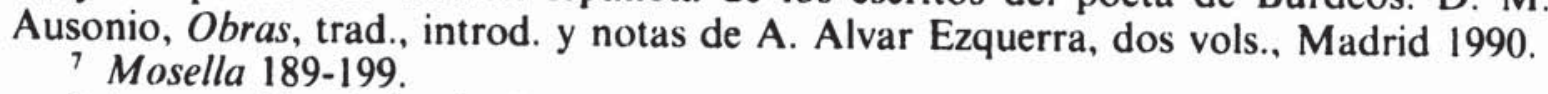

${ }^{8}$ La cuestión de la técnica descriptiva empleada por Ausonio en su Mosella ha merecido la atención reciente de varios estudiosos: Ch.-M. Ternes, "Paysage réel et coulisse Idyllique dans la Mosella d'Ausone», REL 48, 1970, pp. 376-397; D. Gagliardi, "La Poetica dell'Ecphrasis e Ausonio", en sus Aspetti della Poesia Latina Tardoantica, Palermo 1972, pp. 65-89; del propio Ternes, "Éléments de rhétorique dans la Mosella d'Ausone», en La Rhétorique à Rome, Caesarodunum XIV bis, ed. por R. Chevallier, Paris 1979, pp. 153-160; E. J. Kenney, "The Mosella of Ausonius", $G \& R$ 31, 1984, pp. 190-202, a propósito de Z. Pavloskis, Man in an Artificial Landscape. The Marvels of Civilization in Imperial Roman Literature, Mnemosyne Supl. 25, Leiden 1973, pp. 33-39; M. Roberts, "The Mosella of Ausonius: an Interpretation", TAPhA 114, 1984, pp. 343-353; R. Martin, "La Moselle d'Ausone, estelle un poème politique?», REL 63, 1985, pp. 237-253 (en especial p. 249 ss.). 
hombre ya no es sino un elemento más - y no precisamente el más afortunado $\ldots$ en el escenario natural ${ }^{9}$.

El escritor se recrea en esta dificil descripción: no la ha trabajado como imagen feliz pero pasajera; la ha elaborado con una sensibilidad privilegiada, puesta de manifiesto en la mera visualización física del fenómeno del reflejo y en la aceptación del reto que supone su descripción. Y, por si fuera poco, resuelve el problema de forma más que brillante. ¿Merece la pena subrayar esta afirmación? ¿Acaso no resulta de infinita elegancia esa paleta de colores mezclados de los vv. 192-193? ¿Y esos collados que flotan con suaves movimientos sobre la mansa superficie del agua?

5. Ausonio conocía como pocos la tradición literaria que le precedió y sabe usar de ella para crear su propio arte. En mil pasajes de su obra, Virgilio, como cabe esperar, es su maestro; tras él, Ovidio, Horacio y los elegíacos suministran cantidad de lecciones. Pero ninguno de ellos le sirve cuando desea aventurarse por caminos nuevos, a donde le lleva su sensibilidad y la de su tiempo; entonces son los poetas de la Edad Flavia - y, en especial, Estacio ${ }^{10}$ los que le sirven de guía; así, y con respecto al texto que nos ocupa, se señalan como paralelos literarios indudables Stat., Silu. I 3, 17-19: nemora alta citatis / incubuere uadis; fallax responsat imago / frondibus et longas eadem fugit umbra per undas; y II 2, 48-49: cum iam fessa dies et in aequora montis opaci / umbra cadit uitreoque natant praetoria ponto.

$\mathrm{Y}$ es que los poetas de finales del s. I y los del s. Iv debieron sentir a la vez una inmensa admiración por los de la Edad de Augusto y la imperiosa necesidad de descubrir nuevos horizontes, si no temáticos, al menos sí formales. Pero aun con todo, por más que se señalen precedentes de la estética tardoantigua en el momento de los Flavios, hay notas distintivas que impedirian la confusión entre una y otra atmósferas literarias. En algún otro lugar he señalado que, mientras Estacio y sus contemporáneos parecen practicar una poesía desde un a modo de genus superbum, en los del IV se adivina una mayor inclinación por el genus humile, por más que gusten de entretenerse $-\mathrm{y}$ de ello hablaré

"Véase R. P. H. Green, "Man and Nature in Ausonius" Moselle», ICS 14, 1989. pp. $310-315$.

${ }^{10} \mathrm{Y}$ aun con todo, nunca se trata de imitación servil, sino de recreación con intencionalidad y alcances originales; véase C. Newlands, "Naturae mirabor opus: Ausonius' Challenge to Statius in the Mosellan, TAPhA 118, 1988, pp. 403-419. Precisamente, el uso que Estacio - por una parte … y la pintura pompeyana --por otra hacen de la técnica del reflejo y de la realidad engañosa, ha sido estudiado por H. Cančik, Untersuchungen zur lyrischen Kunst des P. Papinius Statius, Spudasmata 13 (Hildesheim 1965), pp. 38-48. Ver también Kenney, art. cit., pp. 199-200. 
más adelante - en juegos malabares con las palabras y sepan cultivar con pleno acierto los registros poéticos de cualquier edad que les precedió. Dicho de otro modo: en aquellos poetas se siente el arte de la poesía desde una perspectiva cuasi grandiosa, de modo que se hace inmenso acopio de recursos literarios y estilísticos, con efectos dramáticos muy efectistas; todo está hinchado. Por el contrario, en éstos, esos mismos recursos pueden ponerse con moderación al servicio de una ékphrasis menos grandilocuente pero asimismo innovadora por su sensibilidad estética; diríase que poetas como Ausonio se dejan perder en el hallazgo de una imagen feliz - como si de un bosque encantado se tratase - y se recrean en ella hasta agotarla. Tal proceder causa que sus creaciones - cuando ponen en ellas todo su empeño - den más la sensación de ser sumas de elementos heterogéneos, mal ensamblados, que estructuras unitarias bien concebidas y mejor acabadas. Pero no acertaríamos si creyésemos que es un mal tan sólo de ellos (en el fondo, ni siquiera es seguro que sea un mal); ése es el ambiente en que se desarrolla la creación artística en su siglo, según se ha señalado ya: los cánones clásicos de unidad y proporción ceden ante el gusto por el detalle ".

6. En un poema escrito en hexámetros dactílicos, equidistante del epilio y el himno, se han introducido elementos líricos que hacen brotar - en su seno-- aromas de una estética diferente. Mas ello, con ser notable, no lo es todo. Tales elementos han revestido, en algún momento, un doble ropaje épico pues al metro empleado ha de sumarse la condición de haber sido presentados por uno de los recursos más característicamente heroicos: la comparación; de modo que ya no puede quedar la menor sombra de duda de que estamos ante un profundo sentido del

"Fundamental para el caso que nos ocupa, es la exposición de J. Fontaine, "Unité et diversité du mélange des genres et des tons chez quelques écrivains latins de la fin du IV e siècle: Ausone, Ambroise, Ammien", en Christianisme et formes littéraires de l'Antiquité tardive en Occident, Vandoeuvres-Ginebra 1977, pp. 425-482 (ahora también en sus Études sur la poésie latine tardive d'Ausone à Prudence, París 1980, pp. 25-82); a propósito de estos versos, señala: "La réussite poétique exceptionnelle de ces vers ne saurait être attribuée à la seule perfection avec laquelle est décrit un spectacle exceptionnellement difficile à enfermer dans les formes du langage. Elle tient, plus profondément, à la puissance de leur signification: dans ces reflets mouvants se trouve livrée au regard l'instabilité essentielle d'un univers où le mouvement des atomes s'exténue en un mouvement des apparences. Une telle intuition métaphysique trouve son expression esthétique (toujours l"“ordre" des formes!) dans la pratique générale, et meme "miniaturisée", du mélange des genres et des tons: transposition technique et littéraire d'un univers de reflets, et tentative d'ajuster le langage même du poète à ce message» (p. 444, n. 1). Amiano Marcelino contemporáneo de Ausonio--, Claudiano ---en la generación siguiente--- y Apolinar Sidonio - un siglo después de que Ausonio escribiese su Mosella -, por no mencionar sino algunos casos, siguen embriagados de tal estética; cf. Roberts, art. cit., p. 344. 
gusto, conscientemente elevado a la categoria poética suprema ${ }^{12}$. Valga, para ilustrar esta impresión, el siguiente pasaje del propio Mosella:

hos Hyperionio cum sol perfuderit aestu, reddit nautales uitreo sub gurgite formas et redigit pandas inuersi corporis umbras. utque agiles motus dextra laeuaque frequentant et commutatis alternant pondera remis, unda refert alios simulacra umentia nautas. ipsa suo gaudet simulamine nautica pubes. fallaces fluuio mirata redire figuras. sic est compositos ostentatura capillos, candentem late speculi explorantis honorem cum primum carae nutrix admouit alumnae; lacta ignorato fruitur uirguncula ludo germanaeque putat formam spectare puellae: oscula fulgenti dat non referenda metallo aut fixas practemptat acus aut frontis ad oram uibratos captat digitis extendere crines: talis ad umbrarum ludibria nautica pubes ambiguis fruitur ueri falsique liguris ${ }^{13}$.

Es la "estética del espejo» ${ }^{14}$ reflejada - permítaseme - con delicadeza suprema en un momento central del poema y con un motivo tan cotidiano como sincero y sencillo ${ }^{15}$. Pues precisamente ese último verso

12 Cf. Mosella 169-171: nec solos homines delectat scaena locorum: / hic ego et agrestes Satyros et glauca tuente's / Naidas...

13 Mosella 222-239. Los modelos clásicos seguros señalados para este pasaje son tan sólo los siguientes: Verg., Aen. III 397: perfunditur ac'quoris aestu; Lucret., IV 96 ss.: postremo speculis in aqua splendoreque in omni / quaecumque apparent nobis simulacra, necessest... Obviamente, Ausonio trabaja la descripción a partir de su propia experiencia visual y poética.

14 Para lo que esa estética significa, cito, de una vez por todas, el libro de J. Baltrušaitis, Ensayo sohre una lèvenda cientifica: al Espejo. Revelaciones, ciencia-ficción $y$ falacias, Madrid 1988 (1978).

is Resulta dificil sustraerse a la impresión de que la uirguncula, sorprendida al verse por vez primera ante un espejo, no sea Bísula, esa muchachita sueva que correspondió como botin de guerra al poeta tras la campaña del 368-369 (es decir, poco antes de que estos versos fueran escritos) y a la que dedicó Ausonio un opúsculo Bissula , conservado sólo de modo fragmentario, pero que revela también un afecto y una ternura inusual. Precisamente, de la parte conservada, merecen destacarse ahora aquellos versos $(4,25-28)$ en donde, de nuevo, se juega con lo falsiverdadero:

sic Latiis mutata bonis, Germana maneret ut facies, oculos caerula, flaua comas.

ambiguam modo lingua facit, modo forma puellam: haec Rheno genitam praedicat, haec Latio.

¿Es casual la repetición en ambos textos de la palabra germana y la alusión a los cabellos? 
es el que para Fontaine ${ }^{16}$ constituye la clave de esta composición, sí, pero también de este modo de entender y ver la realidad, cuyo antecedente más ilustre son las Metamorfosis ovidianas. Nótese cómo, por si fuera poco, la ilusión creada por el efecto del reflejo está, además, subrayada intensamente por los vv. 227 (unda refert alios simulacra umentia nautas), 228 (simulamine) y 229 (fallaces fluuio mirata redire figuras).

Y lo mismo que Ausonio, otro poeta de la Baja Latinidad aunque menos encumbrado y famoso que él - Tiberiano-, también se ha dejado seducir por el mismo efecto. De los poquísimos restos conservados de su obra, dice uno así:

natura sic est fluminis.

ut obuias imagines

receptet in lucem suam ${ }^{17}$

Mas el hombre de la Baja Latinidad no es sensible tan sólo a los reflejos visuales. Hay otra experiencia, la acústica, que permite captar inasibles destellos de la naturaleza y ante cuya belleza los oídos sienten atracción irresistible: me refiero al eco. Resulta sorprendente comprobar el hechizo que tal fenómeno produjo en esos espíritus prestos a recibir modulaciones nuevas o, al menos, sentidas de modo diferente e intenso. Nada de extraño tiene que el propio Ausonio, en diversos lugares de su obra y con intención desigual, deje escapar esa particular percepción del fenómeno natural, y así en Mosella 293-297, se lee:

licet hic commercia linguae

iungere et alterno sermonem texere dictu.

blanda salutiferas permiscent litora uoces,

et uoces et paene manus: resonantia utrimque

uerba refert mediis concurrens fluctibus echo ${ }^{18}$.

En este contexto, nada extraña su fascinación recogida de modo magistral en Epigr. 32, que, a pesar de ser traducción de unos originales griegos ${ }^{19}$, no contradice la suposición planteada: precisamente, el hecho

${ }^{16}$ Fontaine, op. cit., p. 443.

17 Cf. Seru., Ad Verg. Aen. VII 96:

ostendit adeo perspicuam fuisse naturam fluminis ut in eo apparerent imagines nemorum, quas Troianae naues secabant.

$\mathrm{Y}$ a renglón seguido se recogen los versos señalados. La atribución a Tiberiano se debe a una lectura de Baehrens; otros leen Terentianus.

${ }_{18}$ No hay, en este caso, modelo clásico señalado que haya podido servir a Ausonio en la elaboración de estas imágenes.

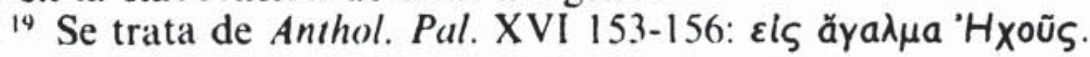


de que el poeta haya querido traducir esos epigramas, tiene mucho que ver con su gusto estético. El resultado es éste:

\section{IN ECHO PICTAM}

Vane, quid adfectas faciem mihi ponere, pictor, ignotamque oculis sollicitare deam?

aeris et linguae sum filia, mater inanis indicii, uocem quae sine mente gero. extremos pereunte modos a fine reducens, ludificata sequor uerba aliena meis. auribus in uestris habito penetrabilis Echo: et, si uis similem pingere, pinge sonum ${ }^{20}$.

Pero me da la impresión de que el gusto estético por un fenómeno natural como es el eco, no se limita, entre los escritores tardoantiguos, a una mera descripción de sus efectos en medio de un paisaje, o a una reflexión poética sobre sus virtudes y propiedades. Puede resultar una coincidencia pero a esta misma época corresponde el apogeo de los versos ecoicos ${ }^{21}$; es bien sabido que los más conocidos de todos son los escritos por Pentadio: de los tres poemas en que los cultiva (De Fortuna, De aduentu ueris, Narcissus), al menos los dos últimos pertenecen, por su temática, de pleno derecho a esta atmósfera estética en donde la naturaleza es elemento central de la poesía y en donde el tema de Narciso ejemplifica de modo paradigmático precisamente la estética del reflejo (en este caso visual):

Cui pater amnis erat, fontes puer ille colebat, laudabatque undas, cui pater amnis erat.

se puer ipse uidet, patrem dum quaerit in amne, perspicuoque lacu se puer ipse uidet...22

Pues bien, el poeta acepta el reto que la naturaleza le propone e intenta imitarla - entiéndase, falsificarla - con el artificio de una modu-

20 El eco, fenómeno bien querido de Ausonio, aparece en otros lugares de su obra: véase Epist. 4, 23-24; 26, 68; o Epigr. 101.

${ }_{21}$ Que, por cierto, también cultivó el propio Ausonio en su Technopaegnion. Véase la obra ya clásica de E. Castorina, Questioni neoteriche. Florencia 1968. p. 263.

22 Narcissus 1-4. No es segura la época en que vivió Pentadio, cuyos poemas, conservados en el Codex Salmasianus, no proporcionan referencias internas datables; no obstante, se le suele identificar con el Pentadius frater a quien dedicó Lactancio su Epitome de las Diuinae institutiones en el 314. Por lo demás, es de factura excelente el pequeño cuadro de estuco de Castallamare di Stabie que representa a Narciso reflejado en el agua; precisamente, es una creación de época flavia; cf. G. Picard, Arte romano, Barcelona 1970 (1965), p. 35. 
lación lingüistica y poética de efectos similares a los del fenómeno natural. De este modo, el poeta tardoantiguo supera los límites, no ya de otros poetas, sino de otros artistas -como los plásticos, según la apreciación hecha por Ausonio en el epigrama anteriormente citado-- y se convierte en un auténtico creador, de poder equiparable momentáneamente al de la propia naturaleza.

\section{La transparencia}

7. Leamos de nuevo a Tiberiano. Lo poco que de él se conserva, se abre con estos tetrámetros trocaicos catalécticos:

Amnis ibat inter arua ualle fusus frigida,

luce ridens calculorum, flore pictus herbido ${ }^{23}$.

En ese segundo verso -..-también referido a un río-- se quintaesencian dos motivos estéticos que mucho agradan a estos poetas de una edad tardia: transparencias y reflejos. Para él no son sino dos trazos de colorista efecto en un poema donde, de nuevo, es un retazo de la naturaleza lo que interesa: las flores y, en especial, la rosa. Muy feliz nos parecería la atmósfera por él dibujada (sic euntem per uirecta pulchra odora et musica / ales amnis aura lucus flos et umbra iuuerat, vv. 19-20), si no supiéramos de las dificultades del período que le tocó vivir. Pero nada de ello trasciende ni en él, ni en sus colegas de quehacer poético.

8. Este breve fragmento de Tiberiano, me sirve para enlazar los anteriores de Ausonio -... que iban de reflejos -., con este otro donde reina el gusto por la transparencia. También pertenece al Mosella:

\footnotetext{
spectaris uitreo per leuia terga profundo, secreti nihil, amnis, habens: utque almus aperto panditur intuitu liquidis sub noctibus aer nec placidi prohibent oculos per inania uenti, sic demersa procul durante per intima uisu cernimus arcanique patet penetrale profundi, cum uada lene meant liquidarum et lapsus aquarum prodit caerulea dispersas luce figuras: quod sulcata leui crispatur harena meatu, inclinata tremunt uiridi quod gramina fundo; usque sub ingenuis agitatae fontibus herbae uibrantes patiuntur aquas lucetque latetque
}

${ }^{23}$ Tiber., I 1-2. 


\begin{abstract}
calculus et uiridem distinguit glarea muscum. tota Caledoniis talis picta ora Britannis, cum uirides algas et rubra corallia nudat aestus et albentes concharum germina bacas, delicias hominum, locupletibus atque sub undis adsimulant nostros imitata monilia cultus. haud aliter placidae subter uada laeta Mosellae detegit admixtos non concolor herba lapillos. intentos tamen usque oculos errore fatigant interludentes, examina lubrica, pisces ${ }^{24}$.
\end{abstract}

El texto es largo pero no tiene desperdicio pues, a mi modo de entender, con él se ilustran con claridad paladina las coordenadas artísticas del poeta de Burdeos. De nuevo, nos encontramos con escasos loci similes que hayan podido servir de inspiración. Para el v. 63 (quod sul('ata...), Ovidio ofrece un lejano eco en Met. XV 725-726: litoream tractu squamae crepitantis harenam / sulcat; Ovidio, igualmente, puede haber suministrado materiales para el v. 64 (inclinata tremunt...), a partir de Am. I 14, 22: ('um temere in uiridi gramine lassa iacet ${ }^{25}$. Los vv. 66-67 (uibrantes patiuntur...) se dicen deudores de Marcial, VIII 68, 6-8: nec tamen uua latet: / femineum lucet sic per hombycina corpus, / calculus in nitida sic numeratur aqua. Y Lucano, a su vez, estaría evocado en el v. 68 (tota Caledoniis...), a partir de VI 68: unda Caledonios fallit turhata Britannos. De todos estos "modelos", ninguno aporta nada realmente esencial al texto de Ausonio, donde lo que en otros autores es marginal $^{26}$ a saber, el efecto de la transparencia como recurso literario -., en el poeta de Burdeos se transforma en el objeto predilecto de su atención; nótese, si no, el generoso pormenor y la seriedad épica - con comparaciones incluidas - con que lo trata.

9. El fragmento presentado se abre con un verso, el 55, que nos introduce, desde mi punto de vista, en una de las claves de esta particular

24 Mosella 55-75.

25 Igualmente distante en cuanto a contexto y efectos, Verg., Georg. II 219: quaeque suo semper uiridi se gramine uestit.

26 Precisamente es, de nuevo, un poeta de la Edad Flavia el que más cerca se encuentra de la descripción de Ausonio; me refiero, naturalmente, al fragmento aducido de Marcial. Junto a ese precedente, hay que situar otro de un amigo del poeta bilbilitano, de Plinio el Joven, que en Epist. VIII 8, 2, escribe:

modicus collis adsurgit, antiqua cupressu nemorosus et opacus. hunc subter exit fons et exprimitur pluribus uenis sed imparibus, eluctatusque quem facit gurgitem lato gremio patescit, purus et uitreus, ut numerare iactas stipes et relucentes calculos possis.

Ver Kenney, art. cit., p. 197. 
estética. La palabra uitreus (y el correspondiente sustantivo uitrum, con toda su familia de derivados) es ya conocida de los poetas clásicos, incluso en su acepción de adjetivo usado con valor metafórico: Virgilio dice uitrea te Fucinus unda (Aen. VII 759); por otra parte, Horacio (Carm. III 13, 1) escribió o fons Bandusiae splendidior uitro. Mas en ninguno de los dos casos se referían esos poetas a la propiedad transparente del cristal por la simple y llana razón de que, cuando ellos escribieron, no se conocía aún la técnica de fabricación de vidrios transparentes; eran, o bien totalmente opacos, con decoraciones profusas, o a lo sumo translúcidos y de variados colores. Si acaso, Virgilio y Horacio se refieren a otras propiedades del cristal, como puedan ser su textura brillante o su fragilidad. La fabricación de vidrios completamente transparentes no se alcanzó en la parte oriental del Imperio, hasta mediados del siglo I, y se generalizó en Occidente sobre todo a lo largo del siglo III, gracias precisamente a la excelente y abundantísima producción de los talleres de Colonia, muy próxima a la Tréveris ausoniana ${ }^{27}$. Con la expansión de tan bellos como perfectos objetos de vida cotidiana se pudo generalizar la comparación "fuente, o río, más transparente que el cristal» ${ }^{28}$. Los poetas - y los artistas del momento - aprendieron entonces a ver con ojos nuevos la labor de la naturaleza que, con infinita sencillez y sin esfuerzo ninguno, conseguía efectos maravillosos que tan sólo a duras penas el hombre conseguía alcanzar e imitar. El progreso de la técnica no hacía sino poner de manifiesto cada vez con mayor evidencia la fuerza y el enigma del mundo circundante.

Ausonio muestra una sensibilidad propia ante el fenómeno de la transparencia y ha asimilado la obra de la naturaleza con la obra del hombre; en efecto, pocos versos antes él mismo ha reconocido de forma paladina su éxtasis ante el prodigio que se despliega ante él, exclamando:

I nunc et Phrygiis sola leuia consere crustis tendens marmoreum laqueata per atria campum.

27 Véase, por ejemplo, A. García y Bellido, Arte romano, Madrid 1972, pp. $244-$ 245 y 808-812; M. Vigil Pascual, El vidrio en el mundo antiguo, Madrid 1969.

${ }_{28}$ De hecho, ya Estacio utiliza el adjetivo uitreus aplicado al mar en un pasaje donde no sería fácil decidir su significado exacto, si bien me inclinaría por la acepción de 'brillante', pues no parece la transparencia una de sus propiedades más destacadas; cf. Aquileida I 26: uitreo sub gurgite. Mas el uso nada casual que Ausonio hace de tal adjetivo con valor de 'transparente' se reitera en Mosella 28: uitreoque lacus imitate profundo; es menos segura esa acepción en Mosella 223: reddit nautales uitreo sub gurgite formas (donde el modelo de Estacio parece haber actuado); o en Mosella 418-419: Caeruleos nunc, Rhene, sinus hyaloque uirentem / pande peplum (donde hyalus sustituye como sinónimo a uitrum, creo que también con la acepción de 'brillante' o de 'reflectante'). 
ast ego despectis, quae census opesque dederunt, naturae mirabor opus... ${ }^{29}$

Al fin y al cabo, las obras más bellas son las que la naturaleza produce de modo espontáneo y el hombre se siente ante ellas como un espectador de insignificantes proporciones y recursos.

10. Mas la transparencia no es un fenómeno sólo observable en limpidas aguas; el ojo de refinada sensibilidad sabe descubrirla también en el aire y distingue las diferentes calidades del cielo; en cierta medida, son precisamente esas diferentes calidades y esos tonos distintos los que confieren a un paisaje y su entorno la posibilidad de ser habitado y querido: de ahí que se haya entendido precisamente a partir del texto que cito a continuación - el Mosella, cuyo valle goza de un cielo transparente frente a la oscuridad de los bosques germanos y sus cielos pesados, como un poema que, entre otras cosas, contrapone dos mundos muy diferentes, la civilización a la barbarie:

purior hic campis aer Phoebusque sereno

lumine purpureum reserat iam sudus Olympum.

nec iam, consertis per mutua uincula ramis,

quaeritur exclusum uiridi caligine caelum:

sed liquidum iubar et rutilam uisentibus aethram

libera perspicui non inuidet aura dei ${ }^{30}$.

\section{Los claroscuros}

11. Los fenómenos naturales del reflejo (visual o acústico) y de la transparencia, se complementan con otros que confieren mil matices distintos al paisaje; pues la naturaleza, a los ojos de quien tiene sensibilidad para reconocerlos, se muestra pródiga en efectos de bella factura y de dificil emulación: entre otros, los claroscuros de la luz tamizada entre las hojas de los árboles frondosos, las neblinas que desdibujan

29) Mosella 48-51. En el último verso hay un significativo quiebro de Stat., Silu. III 1. 119: longaeuum mirantur opus. Merece la pena insistir en esta concepción de la natura artifex, ya señalada, por ejemplo, en el art. cit. de J. Fontaine, p. 442, n. 1, precisamente en un momento de gran esplendor de la técnica.

31) Mosella 12-17. Este pasaje, sabiamente glosado por R. Martin, art. cit., p. 250 ss., ha sido comparado con la bajada de Eneas a los Infiernos y la llegada a los Campos Elíseos; incluso hay expresiones coincidentes con las virgilianas (y con lugares de otros poetas): cf. Verg., Aen. VI 640: largior hic campos aether et lumine uestit purpureo; Lucan., III 400: lucus erat... obscurum cingens conexis aera ramis; Verg., Aen. XI 187: caligine caelum. Ver W. Goerler, "Vergilzitate in Ausonius' Mosella", Hermes 97, 1969, pp. 94-114. 
perfiles y obligan a intuir más que a ver, las transiciones de esencia confusa entre la noche y el día, el día y la noche. En cierta ocasión, al enviar una carta Ausonio a su amigo Símaco, confesaba, como elogio supremo, que los escritos de su antiguo compañero le hacian sentir una sensación muy especial:

hoc me uelut aerius bratteae fucus aut picta nebula non longius, quam dum uidetur, oblectat; chamaeleontis bestiolae uice, quae de subiectis sumit colorem, aliud sentio ex epistula tua, aliud ex conscientia mea ".

El poeta nos hace una paladina declaración de gustos estéticos, dominada en buena medida a partir de los efectos causados por el reflejo en el metal pulido del espejo, y por la niebla ${ }^{32}$ en la cercanía; además, la referencia al color cambiante del camaleón subraya otra de las características de esta sensibilidad - lo falsiverdadero, el trampantojo - de la que hablaré más adelante. Tal declaración queda confirmada por numerosas observaciones algunas de ellas ya mencionadas - que salpican su obra; con frecuencia, efectos diversos se aúnan en una misma descripción, como es el caso de los versos 55-75 del Mosella, en donde la transparencia permite el juego del claroscuro, perfectamente intuido por Ausonio en el v. 66 (lucetque patetque), que da una respuesta intencionada a los vv. 55-56 (spectaris uitreo per leuia terga profundo, secreti nihil, amnis habens). Ese mismo juego entre transparencias y claroscuros está presente también en los versos 12-17 (ya comentados), que dan, a su vez, contestación a los versos 1 (nehuloso flumine) y 5 (nemorosa per auia) ${ }^{33}$.

12. En el Cupido cruciatus -descripción de un fresco que decoraba el comedor de un amigo de Ausonio en Tréveris -- los juegos de luces y sombras están subrayados con intensidad. El cuadro representaba la crucifixión del Amor (o, tal vez mejor, el sacrificio de Adonis, como escena de iniciación tardohelenística) y de él debía emanar una atmósfera densa y ominosa, donde la noche cobraba una vida incierta a la luz. de las antorchas en las manos de las heroínas de antaño (vv. 71-72: nonnullae flammas quatiunt trepidaeque minantur / stridentes nullo igne faces). Esa atmósfera - dificil de expresar- ha sido atinadamente recogida por el poeta con hallazgos felices. Así, en los vv. 1-9:

${ }^{31}$ Epist. I 10-13. En la puntuación de este pasaje no sigo la edición de Prete.

32 Recuérdese al respecto el comienzo de la carta dedicatoria del Cupido cruciatus, enviado a Gregorio Próculo: En umquam uidisti nehulam pictam in pariete? uidisti utique et meministi.

${ }^{33}$ Nótese en el v. 15: exclusum uiridi caligine caelum. 
Aeris in campis, memorat quos musa Maronis, myrteus amentes ubi lucus opacat amantes. orgia ducebant heroides et sua quaeque. ut quondam occiderant, leti argumenta gerebant. errantes silua in magna et sub luce maligna inter harundineasque comas grauidumque papauer et tacitos sine labe lacus, sine murmure riuos: quorum per ripas nebuloso lumine marcent fleti, olim regum et puerorum nomina, flores ${ }^{34}$.

O en los vv. 45-46:

quas inter medias furuac caliginis umbram dispulit inconsultus Amor stridentibus alis.

Mas, finalmente, haciendo uso de su peculiar modo de entender la creación poética, Ausonio confunde de nuevo al espectador lector en este caso (recuérdese el derisus de Mosella 196) y lo que parecia la descripción lograda de un cuadro, se convierte en un instrumento de engaño donde ya nada es lo que parece ser:

Talia nocturnis olim simulacra figuris exercent trepidam casso terrore quietem. quac postquam multa perpessus nocte ('upido effugit, pulsa tandem caligine somni euolat ad superos portaque cuadit eburna ${ }^{35}$.

13. Ausonio fue capaz de abordar con soltura la descripción de los momentos fugaces, en que se pueden vivir experiencias tan intensas como breves; esos momentos inasibles encantan su sensibilidad y se recrea en ellos, de modo muy diferente a los clásicos. Para Virgilio, la transición entre la noche y el dia el amanecer dura el instante preciso de un hexámetro dactílico: iamque rubescehat stellis Aurora fuga-

${ }^{34}$ Las fuentes de este pasaje se encuentran, naturalmente, en Verg., Aen. VI 887 (aeris in campis); VI 443 (myrtea circum silua :'git); VI 451 (errabat silua in magna); VI 270 (suh luce maligna) y Ecl. III 106 ss. (inscripti nomina regum... flores). Cf. también Horat., Epist. I 10, 21 (cum murmure riuum) y Catul. 68, 55 (maesta ne'que adsiduo tabescere lumina fle'tu).

"Cupido cruciatus 99-103. Cf. Verg., Aen. VI 898: portaque emittit eburna. No es el único lugar en que Ausonio mezcla realidad y ensueño; véase Ephemeris 7, 2243; o Bissula 3, 13-16: me'um post pocula si quis / legerit, hic sapict: / sed magis hic sapiet, si dormiet et putet ista / somnia missa sibi. Para el poema en relación con las bellas artes de su tiempo, ver W. Fauth, "Cupido cruciatur". (irazer Beiträge 2. 1974, p. 39-60). 
$t_{i s^{36}}$. El poeta tardoantiguo, sin embargo, demora felizmente el paso del día a la noche, de modo que la luz incierta del atardecer hace brotar mil matices inesperados, entre los que reina el paisaje reflejado en el agua; observación, por lo demás, plenamente atinada pues la luz meridiana conviene mejor al efecto de la transparencia. Me he referido más arriba a Mosella 189-199, para subrayar la encantadora eficacia de la descripción del reflejo; pues bien, hay en esos mismos versos alusiones precisas al momento del día en que se produce: seras cum propulit umhras / Hesperus (192-193); y en este contexto me parecen innecesarias, o por lo menos desafortunadas, las correcciones propuestas a la lectura que los códices ofrecen en el v. 206: dum spectat transire diem... ${ }^{37}$

\section{Lo falsiverdadero}

14. Probablemente no hay efecto más buscado por los artistas tardoantiguos en general y por los poetas en particular, que éste. En realidad, y como decía al principio de estas páginas, alcanzar la adecuación perfecta entre la realidad (¿la verdad?) y la creación artística (que supone siempre una limitación de la realidad y, por tanto, una falsedad) parece ser la razón de su arte. Hemos ido viendo a lo largo de las páginas anteriores cómo el escritor de la Baja Latinidad intenta superar a sus

36 Aen. III 521. Un poeta como Julio Montano de la época de Tiberio solia abusar de los amaneceres y de los crepúsculos en sus versos, pero al menos en los fragmentos que nos han llegado (Morel 1-2) nada hay que pueda ser comparable a los atrevidos ensayos de Ausonio. Vid. H. Bardon, "L'aurore et le crépuscule», REL 1947, p. 82 ss.; y su Litterature latine inconnue, II, pp. 59-60.

${ }_{37}$ Una dificil construcción sintáctica en los versos 204-207 hace a L. Bieler, «Zur Mosella des Ausonius: Cliens in der Bedeutung Colonus», RhM 86, 1937, pp. $285-$ 287 , sustituir diem, unánimemente ofrecido por los manuscritos, por un cliens (para que spectat y posthabet puedan tener un sujeto explícito); pero cliens hay que explicarlo, a su vez, como metonimia de colonus («mientras el colono les ve pasar»); el resultado, a pesar de los equilibrios de critica textual dudosamente aceptables, es, a mi modo de entender, peor que el texto original, menos poético y más artificial, mientras que no deja resueltos todos los problemas sintácticos; con todo, Prete prefiere la lectura propuesta por Bieler; no así, Ternes. Otros editores suponen que aquí falta una parte del v. 206 (a partir de spectat) y otro fragmento del verso siguiente (antes de transire); dicho de otro modo: al copiar el texto se habria producido un salto visual del spectat de un verso al transire del siguiente. Por mi parte, no creo que sea imprescindible suponer un sujeto para posthabet o spectat distinto a impubes manus, bien cercano a ambos; sería redundante haberlo repetido. Entiéndase, por tanto, una traducción literal de este modo:

¡ir de alegres patronos de proa a popa

y de su gente, imberbe aún, sobre la espalda de la corriente!

mientras ven cómo se va el día, sus trabajos con el juego posponen (...) 
modelos, desde un estricto respeto de los mismos; poco hay en aquéllos que no se encuentre de una u otra forma en éstos. Mas el poeta tardío también tiene su propia sensibilidad, de modo que, recogiendo formas y contenidos ya usados, los reelabora con un sentido de la estética y de la proporción bien distintos. La insistencia en alcanzar las fronteras más dificiles entre la realidad y el arte para fundirlos en una misma cosa - de la mano de los avances técnicos del momento - ha llevado a estos poetas a trabajar las distintas especies de carmina figurata. Así, Optaciano Porfirio no es un extravagante versificador de raras manías; es un producto consecuente de la época que le tocó vivir, en la que se ensayó todo género de posibles salidas a los angostos senderos por los que transcurría la creación poética desde el siglo de Augusto. Es preciso entenderlo de este modo, por más que, desde nuestra posición estética, su intento - y los de otros contemporáneos - sea un fracaso.

15. Al abrir el libro de los Epigramas de Ausonio, se percibe una neta inclinación hacia los temas que sitúan en primer plano el conflicto entre la verdad --la naturaleza - y la creación del artista; y no me parece casual que con harta frecuencia el objeto de consideración en el epigrama sea precisamente una obra de arte. Por ejemplo, los Epigr. 8-13 constituyen un juego poético a propósito de los conceptos de lo verdadero, lo similar y lo diferente, a partir de los retratos escultórico y pintado de un rétor:

Rhetoris hace Rufi statua est: nil uerius; ipse est, ipse: adeo linguam non habet et cerebrum.

et riget et surda est et non uidet: haec sibi constant; unum dissimile est: mollior ille fuit ${ }^{3 \times}$.

Creo que también han nacido de otras obras de arte -aunque no se diga expresamente muchos más epigramas, como los dedicados a temas mitológicos (97-105; Hilas y las Náyades, Narciso ${ }^{34}$, Eco, Hermafrodito y Sálmace, Apolo y Dafne); en todos ellos, bajo la sombra espesa y enorme de las Metamorfosis ovidianas, florecen los instantes en que la realidad se transforma y el espectador se pregunta sobre la esencia del ser que contempla en plena mutación ${ }^{40}$. Ese espectador ha podido

${ }^{38}$ Epigr. 9. Este conjunto de epigramas traducen originales de la Anthol. Pal.; mas resulta sobradamente significativo, a propósito de los gustos estéticos del poeta, el hecho de que Ausonio los haya escogido para trasladarlos al latín.

${ }^{34}$ Vid. supra, $\$ 6$.

41) Es el momento en que, por ejemplo, la vida da paso a la muerte, descrito de modo detallado y minucioso por el poeta de Burdeos, en Mosella 250-282, a propósito de la muerte de un pez, de entre los que recuerdo los vv. 259-269: 
ser un artista plástico, pero en este caso es también un poeta enamorado del juego que propone lo falsiverdadero:

Furitis procaces Naides

amore saeuo et irrito:

ephebus iste flos erit ${ }^{41}$.

Mas ningún conjunto de epigramas ausonianos ejemplifica mejor esta sensibilidad estética que el dedicado a la Bucula Myronis; son los epigramas $68-75$, de entre los que uno sólo vale por todos:
Bucula sum, caelo genitoris facta Myronis aerea: nec factam me puto, sed genitam.
sic me taurus init, sic proxima bucula mugit, sic uitulus sitiens ubera nostra petit.
miraris, quod fallo gregem? gregis ipse magister inter pascentes me numerare solet ${ }^{42}$.

El artista ha alcanzado, con su obra maestra, el engaño perfecto: la propia ternera - real para reses y boyero - se miente a si misma pues, sabedora de su condición inerte, finge hablarse en una doble prosopopeya, la de la estatua viviente y la del animal parlanchín ${ }^{43}$.

16. Esta veneración poética - artística, en general -.. por lo falsiverdadero, es una coordenada indispensable para enjuiciar la estética dominante de la creación tardoantigua. Por ello no debe extrañar que sea también este período el del florecimiento de los centones: su confec-

exultant udae super arıda saxa rapinae

luciferique pauent letalia tela diei.

cuique sub amne suo mansit uigor, aere nostro

segnis anhelatis uitam consumit in auris.

iam piger inualido uibratur corpore plausus,

torpida supremos patitur iam cauda tremores

nec coeunt rictus, haustas sed hiatibus auras

reddit mortiferos expirans branchia flatus.

sic ubi fabriles exercet spiritus ignes,

accipit alterno cohibetque foramine uentos

lanea fagineis adludens parma cauernis.

${ }^{41}$ Epigr. 98. El caso de Hermafrodito quintaesencia incluso con su nombre el ejemplo de la realidad engañosa e incierta; tan sólo éste traduce un original griego conocido (Anthol. Pal. IX 783).

42 Epigr. 68, confeccionado a partir de varios originales de la Anthol. Pal.

${ }^{43}$ Podría seguir mostrando ejemplos de la estética del engaño, como es el caso de los epigramas 4 (el falso médico), 5 (el hombre que imita los ruidos de los animales y no sabe hablar), 18 (el histrión que se cayó imitando a Capaneo), 38 (el viejo disfrazado de joven para obtener el favor de una prostituta), etc. Recuérdese, además, lo dicho anteriormente a propósito de Bissula, medio romana, medio germana. 
ción se constituye en un eslabón más de tal concepción artística, en este caso trasladada a la creación literaria; al fin y al cabo, ya ha sido puesta de manifiesto la relación existente entre este tipo de artificio poético y las artes plásticas de la época, como los mosaicos o los relieves que decoran el arco de Constantino ${ }^{44}$. Es bien sabido que el propio Ausonio dictó con insistencia las leyes del género al componer su propio Cento nuptialis:

centonem uocant, qui primi hac concinnatione luserunt. solae memoriae negotium sparsa colligere et integrare lacerata (...). accipe igitur opusculum de inconexis continuum, de diuersis unum, de seriis ludicrum, de alieno nostrum (...). hoc ergo centonis opusculum ut ille ludus tractatur, pari modo sensus diuersi ut congruant, adoptiua quae sunt, ut cognata uideantur, aliena ne interluceant ${ }^{45}$.

De tal modo que el lector, una vez más engañado, no sabria contra quién cargar el enojo que pudiera producirle tan vergonzante página, pues no es Ausonio quien la escribe, sino Virgilio quien la escribió: et si quid in nostro ioco aliquorum hominum seueritas uestita condemnat, de Vergilio arcessitum sciat ${ }^{46}$. Cualquier otro centón del momento obedece a los mismos presupuestos estéticos y técnicos, sea su contenido cristiano o licencioso. De igual modo, lo falsiverdadero está presente en buena parte de los efectos descritos anteriormente, fundiéndose unas veces con los reflejos, otras con las transparencias y también con los claroscuros.

4t A propósito de este último, dice Garcia y Bellido, op. cit., pp. 679-680: «De este periodo es una de las obras más sobresalientes del arte romano: el arco que se alza, solemne y grandioso, en la llamada Vía Triunfal (...). Aunque en su concepción general es obra totalmente constantiniana, en su revestimiento decorativo procede, en gran parte, de otros monumentos que, despojados de él por razones ignoradas (...), sirvieron de decoración al nuevo arco. Las columnas corintias de los frentes proceden de un monumento de Domiciano: los relieves del interior del arco central y los dos lados menores del ático, de otro de Trajano, las estatuas de bárbaros cautivos, etc. Ello justifica la comparación con la corneja de la fábula de Esopo y la certera frase de que en el arco constantiniano tenemos un verdadero palimpsesto del arte imperial romano". Vid. también J. Fontaine, "La poésie chrétienne 'mondaine" du centon de Proba aux petits vers d'Ausone», en su libro Naissance de la poésie dans l'Occident chrétien. (Esquisse d'une histoire de la poésie latine chrétienne du III' au VI siécle), París 1981, pp. 95-110, en especial, p. 103: "ces centons virgiliens sont contemporains de l'opus sectile en fragments de marbres divers, de la mosaïque polychrome, des remplois de sculptures classiques ou du Haut Empire en de nouveaux ensembles architecturaux qui leur donnent un nouveau sens".

${ }^{45}$ Cento nuptialis, epístola dedicatoria 3-5, 20-22, 43-45.

4h Cento nuptialis X 21-23. 


\section{Colofón}

Tales efectos interesan en el plano de la pura ékphrasis: son observados con una sensibilidad entusiasta y se describen con minuciosidad; pero también interesan en el plano de la mimesis: son recreados en la obra literaria, al igual que lo hacen otros artistas. Ya lo había dicho Horacio en su Ars poetica:

ut pictura poesis: erit quae si propius stes te capiat magis, et quaedam si longius abstes. haec amat obscurum, uolet haec sub luce uideri, iudicis argutum quae non formidat acumen; haec placuit semel, haec decies repetita placebit ${ }^{47}$.

Vt pictura poesis. Así lo entendían también los poetas tardoantiguos, pero la diferencia con respecto a los clásicos - sus modelos- es que ellos no gustaban ni de lo oscuro ni de lo luminoso, sino de la difícil conjunción de ambos efectos. Lejos del siglo áureo intentaron crear, a partir de una sensibilidad estética diferente, una poesía distinta basada, a pesar de todo, en aquel ejemplo de perfección ${ }^{48}$.

Antonio Alvar Ezquerra

${ }^{47}$ Ars poetica 361-365. El tópico de la similitud entre pintura y poesía viene de lejos, al menos desde Simónides de Ceos, según Plutarch., De Gloria Atheniensium; pero también aparece en Plat., Rep. X 605a; Arist., Poet.; o Cic., Tusc. V 39, 114; más tarde, seria objeto de larga discusión en Longin., De lo sublime. La bibliografia al respecto es, igualmente, extensa; véase, al menos, $\mathrm{H}$. Markiewicz, "Vt Pictura Poesis... A History of the Topos and the Problem", New Literary History 18, 1987. pp. 535-558.

${ }^{48}$ Merece la pena, no obstante, señalar que esta estética literaria ha tenido fugaces, pero importantes, precedentes precisamente en la pintura de las decoraciones murales romanas de mediados del s. I a. C. (contemporáneas, por tanto, de la estética de los poetae noui): por ejemplo, el oecus corintio de la Casa del Laberinto en Pompeya; cf. G. Picard, Arte romano, ya cit., pp. 47-48. Vid. R. Winkes, "Zum Illusionismus römischer Wandmalerei der Republik (mit 6 Abbildungen)", $A N R W$, I 4 , 1973, pp. 927-944. 